\title{
KAJIAN ESTETIKA MOTIF UKIR KERATON SUMENEP MADURA HASIL AKULTURASI TIONGHOA
}

\author{
Zainor Ahmad ${ }^{1}$ \\ (Jurusan Pendidikan Seni Budaya, Pascasarjana, Universitas Negeri Surabaya, zainorandi@gmail.com, \\ zainor.18002@mhs.unesa.ac.id, 087755884483)
}

\begin{abstract}
The legacy of ancient objects is the history that there was a civilization at that time, such as a kingdom which was the center of social and cultural society. should be grateful that the kingdoms of the past can still be appreciated today. As in the architecture of the Keraton Sumenep Madura, it gets acculturation from various cultures, namely the Madurese and Chinese cultures. It is possible that the palace carving art got a touch from China. Not only the motifs are beautiful, but they give meaning to every motif displayed on the ornaments of the Sumenep Palace. But in reality there are still many people who do not recognize the local culture. This problem is interesting to be studied further. This paper aims to describe the aesthetic value contained in the ornamental motifs of the Sumenep Madura Palace which is a motif resulting from the acculturation of Madurese and Chinese cultures. This study uses qualitative research methods to describe the various motifs and meanings of the Sumenep Palace ornaments. To obtain data sources, interviews, field observations, and documentation were carried out. The results of the article describe the aesthetic value of the carving ornaments of the Sumenep Madura Palace, namely the Janggoleng motif pattern from the orchid plant, and the Hong bird which is a Chinese motif with the meaning of peaceful life combined with the Burneh plant motif which is a typical Sumenep Madura motif.
\end{abstract}

Keywords: aesthetic tilapia, ornaments, Sumenep Madura Palace

\section{ABSTRAK}

Peninggalan benda kuno merupakan sejarah bahwa telah terjadi sebuah peradaban di masa itu, seperti sebuah kerajaan, pusat masyarakat bersosial dan berbudaya. Patut disyukuri kerajaankerajaan silam masih dapat diapresiasi hingga saat ini. Arsitektur bangunan Keraton Sumenep Madura mendapatkan akulturasi dari berbagai budaya, yaitu budaya Madura dan Tiongkok. Tidak menutup kemungkinan seni ukir keraton pun mendapat sentuhan dari Tiongkok. Bukan hanya motifnya yang indah namun memberikan makna setiap motif yang ditampilkan pada ornamen Keraton Sumenep. Namun kenyataannya, masih banyak masyarakat yang tidak mengenali budaya lokalnya. Permasalahan ini menarik untuk dikaji lebih dalam. Tulisan ini memiliki tujuan mendeskripsikan nilai estetika yang terkandung dalam motif ornamen Keraton Sumenep Madura yang merupakan motif hasil akulturasi budaya Madura dan Tiongkok. Penelitian ini menggunakan metode penelitian kualitatif untuk menguraikan berbagai motif dan makna ornamen Keraton Sumenep. Untuk memperoleh sumber data, dilakukan dengan wawancara, observasi lapangan, dan dokumentasi. Hasil dari artikel ialah mendeskripsikan nilai estetika dari ornamen ukir Keraton Sumenep Madura, yakni adanya pola motif Janggoleng dari tanaman anggrek, serta adanya burung Hong yang merupakan motif Tionghoa dengan makna kedamaian hidup yang dikombinasikan dengan motif tanaman Burneh yang merupakan motif khas Sumenep Madura.

Kata Kunci: nilai estetika, ornamen, Keraton Sumenep Madura 


\section{PENDAHULUAN}

Sejarah merupakan sebuah istilah yang terjadi di masa lampau. Dalam sejarah terdapat ruang lingkup tertentu yang menjadi sebuah perbendaharaan berharga di masa depan. Ruang lingkup sejarah dapat dibagi menjadi empat, yang meliputi sejarah sebagai peristiwa, sejarah sebagai ilmu, sejarah sebagai kisah, dan sejarah sebagai seni (Sumber Sejarah, 2018). Sejarah sebagai seni yang dimaksud adalah sebuah benda karya seni yang dibuat pada masa itu dan menjadi benda peninggalan sejarah. Yang menjadi permasalahan pada masa modern adalah kurangnya apresiasi terhadap peninggalan sejarah, dan kurangnya informasi yang tidak valid, sehingga memberikan rasa ketidaktertarikan generasi muda dalam mempelajari sejarah khususnya peninggalan sejarah lokal di daerahnya.

Peninggalan seni ukir pada ornamen bangunan peninggalan sejarah, seperti pada ornamen keraton, candi, benda pusaka, dan berbagai peninggalan sejarah seni lainya merupakan karya seni yang tinggi. Seniman menciptakan ornamen tersebut tentunya mempunyai berbagai tujuan. Tujuan umum penciptaan ornamen memberikan nilai keindahan pada media yang ditempatinya. Beberapa ornamen melambangkan simbolsimbol tertentu. Untuk memahami maksud dari simbol-simbol tersebut dibutuhkan penelitian terlebih dahulu.

Ukiran Madura, sebenarnya bila ditelaah secara teliti, tidak ada dalam arti luas satu Madura, namun yang dimaksud ukiran Madura, ukiran lokal yang terdapat di Madura. Jelas ukiran yang dimaksud, ukiran yang terdapat di daerah dari keempat kabupatennya, yaitu: Ukiran Gunung Sekar (Sampang), Ukiran Karduluk (Sumenep), Ukiran Aeng Tong-Tong (Sumenep), dan beberapa perajin di Bangkalan dan
Pamekasan yang tidak banyak.

Kesenian suatu daerah dengan daerah lainya sangatlah mudah terpengaruh, tanpa terkecuali seni ukirnya. Adanya pengaruh karya ukir dari luar tak dapat dipungkiri, seniman ukir luar daerah yang diam di Madura dengan berbagai alasan dan waktu yang relatif lama, ataupun sebaliknya, seperti seniman ukir madura yang pergi keluar daerah dalam waktu yang lama dan kembali ke Madura. Walaupun demikian, karena karakter pengukir Madura sudah terbentuk, hasil tiruannya masih tetap menampakkan ciri kepribadianya, yaitu "apa adanya", sehingga masih terlihat kasar. Meskipun ada ukiran yang ditiru, karakter orang Madura tetap dominan. Bentukbentuk yang dibuat menggambarkan alam Madura yang kurang subur dibandingkan dengan daerah lainnya.

Ukiran Madura dalam pengaplikasiannya melekat erat pada bendabenda pakai, sehingga ukiran Madura disebut seni terapan. Ukiran Madura pada masa lampau diukir pada barang apa saja yang pantas dan dapat diukir. Apabila dilihat dari barang-barang yang dihias berupa ukiran, dapat disimpulkan bahwa penduduk Madura sebenarnya perajin seni ukir, khususnya pada Kabupaten Sumenep. Hingga saat ini Kabupaten Sumenep menjadi kota ukir Madura.

Ukiran Madura zaman lampau, tidak hanya sekedar benda mati atau hiasan semata, namun di dalam bentuk-bentuk motifnya mempunyai nilai magis spiritual yang dipercaya tersirat dalam simbol ataupun bentuk motif yang diyakini. Kepercayaan ini masih dipercaya meskipun ada perubahan agama, hingga saat ini motif yang dipercaya dan dijadikan patokan dapat mengusir balak dan mendatangkan ketenteraman.

Seperti halnya motif ukir di Keraton 
Sumenep Madura yang mempunyai nilai artistik dan mempunyai makna di dalamnya. Motif yang diaplikasikan pada ornamen Keraton Sumenep Madura merupakan hasil akulturasi budaya Madura dan Tionghoa.

\section{METODE}

Penelitian ini menggunakan metode penelitian kualitatif untuk menggali informasi dari para informan. Metode penelitian merupakan sebuah teknik atau cara menganalisis yang dilakukan dalam sebuah penelitian untuk mendapatkan hasil penelitian secara jelas dan dapat dipertanggungjawabkan.

Untuk memperoleh data tertulis, seperti arsip, foto dokumen, buku, jurnal, naskah, dan makalah ilmiah, penelitian ini melakukan studi kepustakaan. Untuk memperoleh data visual (artefak peninggalan sejarah) dan sumber-sumber lisan dilakukan studi lapangan menggunakan metode observasi dan wawancara.

\section{HASIL DAN PEMBAHASAN}

Sumenep merupakan kabupaten terakhir yang ada pada sisi timur pulau Madura. Menurut sejarahnya, ada kaitannya dengan kerajaan yang ada di Jawa Timur, yaitu Kerajaan Singosari yang dipimpin oleh Raja Kertanegara. Setelah Aria Wiraraja dipecat dari jabatan menteri, beliau diangkat kembali oleh raja Kertanegara sebagai Bupati Sumenep. Dipimpin seorang Bupati Aria Wiraraja (Banyak Wide) pada tahun 1269, keraton yang berada di Batuputih bekasnya telah lenyap. Setelah pemerintahan Aria Wiraraja, yaitu Aria Bangah di Banasereh dengan keraton yang telah lenyap seterusnya, hingga pemerintahan Panembahan Somala yang sampai saat ini keraton masih bisa berdiri kokoh (Ratnasari,
2002).

Cagar budaya peninggalan keraton ini dibangun di atas tanah milik Penembahan Somala, penguasa Sumenep XXXI. Dibangun Pada tahun 1781 masa pemerintahan kolonial Belanda dengan arsitek pembangunan keraton oleh Lauw Piango salah seorang warga keturunan Tionghoa yang mengungsi akibat Huru Hara Tionghoa $1740 \mathrm{M}$ di Semarang. Keraton Panembahan Somala dibangun di sebelah timur keraton milik Gusti Ayu Rasmana Tirtonegoro dan Kanjeng Tumenggung Ario Tirtonegoro (Bindara Saod) yang tak lain adalah orang tua beliau. Lokasi tepatnya di Jalan dr. Soetomo, kota Sumenep, sebelah timur Gedhong Negeri (Depdikbud. 1980).

Dari berbagai bangunan keraton Sumenep Madura yang didesain arsitek Lauw Piango menghasilkan desain kolaborasi antara bangunan Tionghoa, Eropa dan tentunya tidak menghilangkan karakteristik dari Madura, yang terlihat dari motif-motif ornamen yang menghiasi pendopo agung dan pintu yang ada di karaton dhelem.

Untuk mengetahui karya seni peninggalan sejarah, diperlukan pemahaman tentang sejarah (Sartono Kartodirdjo, 1993). Menurutnya, sejarah merupakan bentuk penggambaran pengalaman kolektif di masa lalu, dan untuk mengungkapnya dapat melalui aktualisasi dan penetasan pengalaman masa lalu. Menceritakan suatu kejadian adalah cara membuat hadirnya kembali peristiwa tersebut dengan cara mengungkapkan verbal.

Burung Hong (Fenghuang) bahasa Mandarin: (鳳凰); pinyin fènghuáng; Bahasa Jepang: hōō; Bahasa Korea: 봉황bonghwang; (Phượng Hoàng) merupakan spesies burung dalam mitologi Tiongkok. Burung yang jantan 
disebut feng dan burung betina disebut huang. Pada masa sekarang ini perbedaan kelamin tersebut jarang lagi dipakai. Fenghuang kerap ditemukan berpasangan dengan naga yang memiliki konotasi jantan. $\mathrm{Di}$ dunia barat, fenghuang sering dihubungkan dengan makhluk mitologi finiks (Home Budaya, 2014).

Pada kalangan Tionghoa maupun Indonesia, Fenghuang sendiri biasanya dikenal dengan nama hong. Biasanya dilafalkan berpasangan dengan makhluk mitologi naga, sehingga dilafalkan menjadi leng-hong. Pada masa Tiongkok kuno motif fenghuang sering ditemukan pada dekorasi pernikahan bersamaan dengan makhluk mitologi naga pada keluarga ningrat. Ini disebabkan tradisi kuno Tiongkok yang menganggap dua makhluk metologi naga dan feniks sebagai simbol hubungan antara suami dan istri, sebuah bentuk metafora antara yin dan yang.

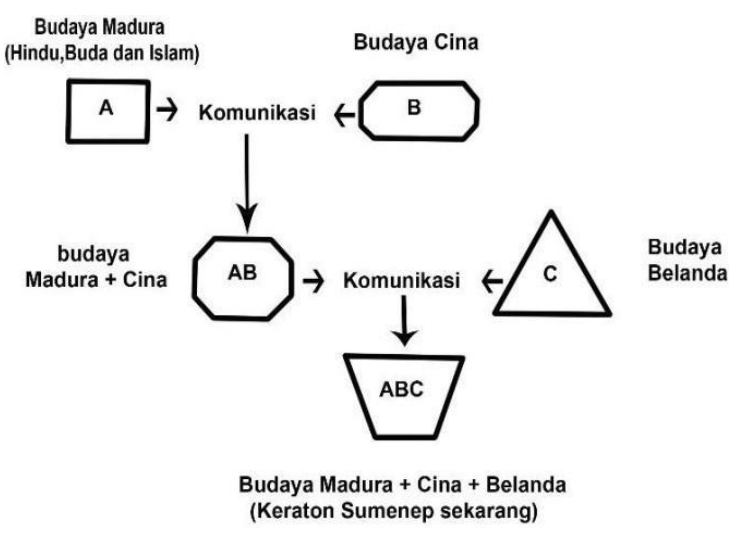

Gambar 1. Akulturasi budaya terciptanya arsitektur Keraton Sumenep Madura.

Tidak menutup kemungkinan dari skema akulturasi budaya di atas berpengaruh terhadap ornamen yang menghiasi Keraton Sumenep Madura sebagai akulturasi dari budaya Tiongkok.

Gustami (2008:4) mengungkapkan pengertian ornamen sebagai berikut:

Ornamen adalah komponen produk seni yang sengaja ditambahkan atau sengaja dibuat untuk tujuan sebagai hiasan suatu benda. Di samping tugasnya menghiasi yang sifatnya implisit menyangkut segi-segi keindahan, misalnya untuk menambah indahnya sesuatu barang sehingga lebih bagus dan menarik. Di samping itu di dalam seni ornamen sering ditemukan pula nilai-nilai simbolik atau maksud-maksud tertentu yang ada hubungannya dengan pandangan hidup (filsafat hidup) dari manusia atau masyarakat yang menciptanya, sehingga suatu benda yang dikenai seni ornamen itu akan mempunyai arti yang lebih bermakna, disertai harapan-harapan yang tertentu pula.

Terkait kutipan yang menjelaskan tentang pengertian ornamen di atas, dapat diketahui bahwa ornamen berfungsi untuk menghiasi suatu benda, agar memiliki keindahan dan mampu mencapai maksud tertentu. Begitu juga dengan hiasan ornamen yang terdapat pada pintu Keraton Sumenep Madura berfungsi sebagai penghias pintu, dan juga memiliki maksud tersendiri.

Ornamen yang terdapat pada keraton Sumenep Madura merupakan stilisasi dari alam. Stilisasi adalah penggubahan bentuk-bentuk di alam dalam seni untuk disesuaikan dengan suatu bentuk artistik atau "gaya" tertentu, seperti yang banyak diterapkan dalam ornamen atau ragam hias. Berkaitan dengan kata "gaya" ada kalanya stilisasi disebut "penggayaan" berasal dari bahasa Inggris "stylization". Stilisasi merupakan proses penciptaan ragam hias melalui tahap-tahap penyederhanaan (abstraksi) atau penggayaan suatu bentuk dasar yang menjadi titik tolaknya, sehingga bentuk "baru" yang dihasilkan berkarakter lebih sederhana dan tidak realistik.

Guntur (2004) menyatakan dasardasar penyusun ornamen (prinsip ornamen) sebagai berikut: 
1. Paduan Harmoni (Selaras)

Perpaduan/pengorganisasian unsurunsur seni rupa tujuan akhirnya adalah harmoni. Harmoni atau selaras merupakan paduan unsur-unsur yang berdekatan, apabila unsur-unsur estetika dipadu secara berdampingan maka akan timbul keserasian (harmony)

2. Paduan Kontras

Kontras merupakan paduan unsurunsur yang berbeda tajam. Gelombang panjang pendek yang tertangkap oleh mata yang ditimbulkan melalui ketajaman warna.

3. Paduan Irama

Paduan irama merupakan pengulangan unsur-unsur pendukung atau repetisi, pengulangan tersebut dibatasi dengan adanya kontur yang selaras.

Ornamen Keraton Sumenep Madura mempunya tiga prinsip yang dijelaskan di atas, seperti halnya pemilihan warna yang terdapat pada motif Sulur- suluran pintu Keraton Sumenep Madura yang mempunyai kontras antara perpaduan warna merah tua dengan warna emas. Ornamen Keraton Sumenep mempunyai irama terbukti dari pengulangan pola motif Janggoleng pada ornamen Keraton Sumenep Madura, sehingga ornamen keraton Sumenep merupakan ornamen yang harmonis.

Djelantik, (1999) menjelaskan bahwa semua benda atau peristiwa kesenian mengandung tiga aspek yang mendasar, yakni:

4. Wujud atau rupa (appearance), sesuatu yang tampak oleh indra (visual), baik konkret maupun abstrak;

5. Bobot atau isi (content, substance), makna yang terkandung dalam karya seni yang berupa konsep;
6. Penampilan, penyajian (presentation), display dalam karya seni yang berkaitan dengan talenta dan media yang disajikan.

Adapun beberapa motif yang ada pada pintu Keraton Sumenep Madura di antaranya sebagai berikut:

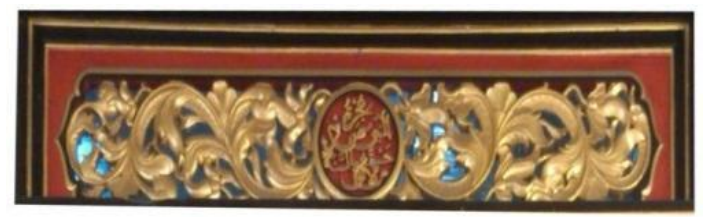

Gambar 2. Ornamen di Atas Pintu Keraton Sumenep

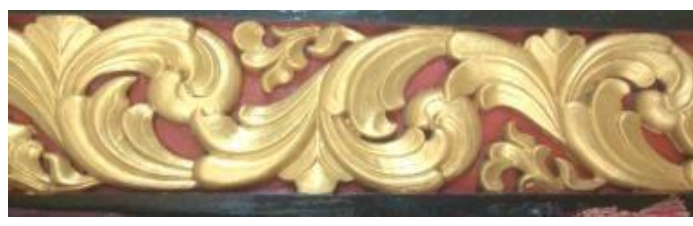

Gambar 3. Ornamen pada Kolom Pintu Keraton Sumenep

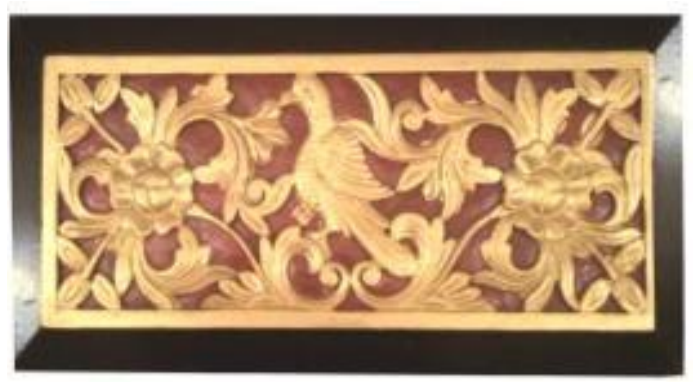

Gambar 4. Ornamen pada Daun Pintu Keraton Sumenep 
Terbentuknya motif pada Keraton Sumenep Madura yang merupakan akulturasi antara Madura dan Tionghoa:
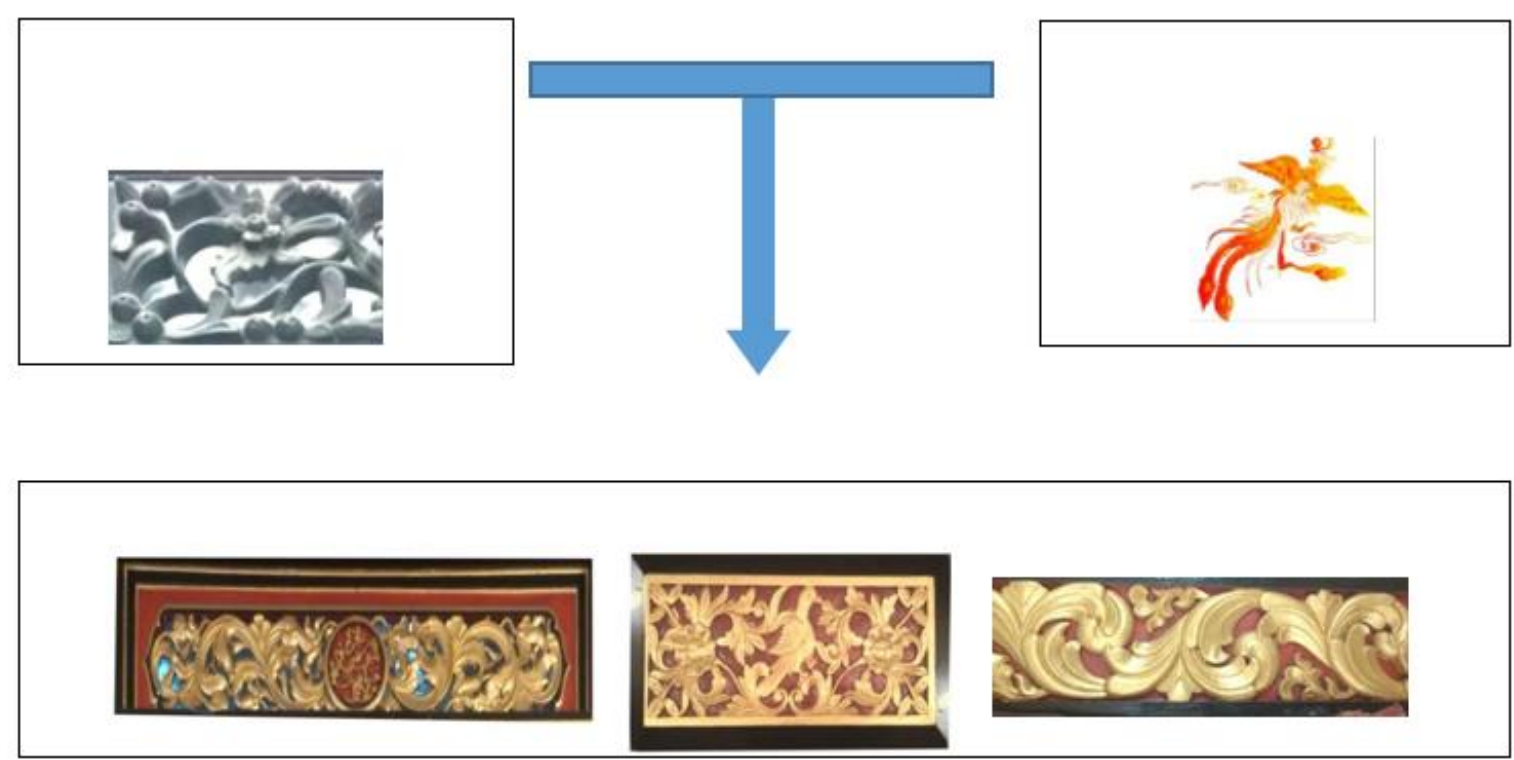

Gambar 5. History Terbentuknya Motif Janggoleng yang Terdapat pada Ornamen Pintu Keraton Sumenep Akulturasi Tionghoa

Akulturasi atau culture contact yang dikemukakan (Koentjaraningrat dalam Suyani, 2013,73) bahwa pertama, suatu kebudayaan yang dihadapkan dengan unsur-unsur dari kebudayaan asing yang sedemikian rupa, sehingga unsur-unsur dari kebudayaan asing itu lambat laun diterima dan diolah ke dalam kebudayaan sendiri tanpa menyebabkan hilangnya kepribadian budaya itu sendiri.

Akulturasi budaya sangat pengaruh terhadap motif Janggoleng yang terdapat di Keraton Sumenep. Hal ini dapat dilihat pengambilan motif dari ornamen Cina, namun tidak hanya pada bentuknya, pengaruh akulturasi budaya berpengaruh pada warna yang dipakai pada ornamen Keraton Sumenep. Warna ornamen ukir khas Sumenep menggunakan warna hijau muda, hijau tua, biru, kuning dan merah kecoklatan. Namun, pewarnaan ornamen yang terdapat di Keraton Sumenep mengadopsi dari warna gold yang dipakai di Cina.

\section{NILAI ESTETIKa PADA MOTIF PINTU KERATON} SUMENEP MADURA

a. Ornamen di Atas Pintu Keraton Sumenep Madura

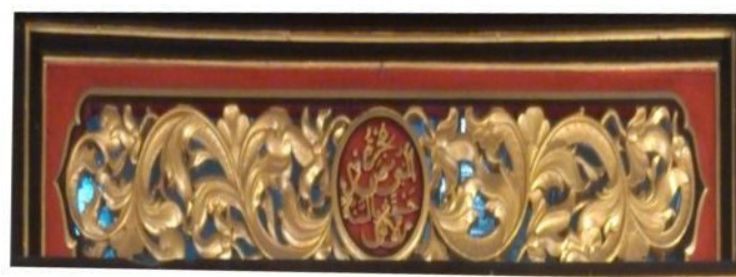

Ornamen yang terdapat di atas pintu keraton pada gambar 2. selain indah dengan motif anggrek sebagai motif pokok, dengan warna gold yang memberikan nilai elegan juga mempunyai makna yang tersirat dalam motifnya. Ornamen yang terdapat di atas pintu Keraton Sumenep Madura tidak hanya dibuat dengan tujuan menghias atau memperindah pintu keraton. Di balik nilai keindahanya terkandung nilai makna dari motif anggrek yang berbunga menimbulkan rasa senang dan kagum pada ukiran keraton 
bagi pengapresiasinya. Motif ini melambangkan kemakmuran, kesempurnaan bagi sang raja yang mendiami sebuah Keraton Sumenep.

Ornamen ini disajikan menggunakan teknik ukir karawangan pada kayu jati, dengan warna gold menjadi warna pokoknya dengan warna merah di pembatas ornamen memberikan kesan kontras terhadap motif yang ditonjolkan yaitu motif anggrek berbunga.

\section{b. Ornamen pada Kolom Pintu Keraton Sumenep Madura}

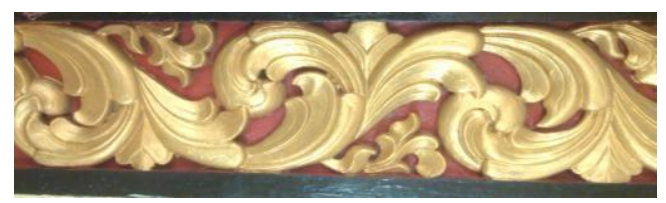

Ornamen yang terdapat kolom pintu keraton yang indah pada gambar 3. juga mempunyai makna yang tersirat dalam motifnya. Ornamen yang terdapat pada kolom pintu Keraton Sumenep Madura tidak hanya dibuat dengan tujuan menghias atau memperindah pintu keraton. Namun, di balik nilai keindahan dari motif anggrek yang menggulung sepanjang kolom pintu memberikan rasa kagum bagi orang yang melihatnya.

Makna ornamen dijelaskan Moh. Soleh, 2020. " motif okeran Sumenep minangka motif sê ê kala' dhâri kembhâng anggre' motif kasebbut ghâduan artê katarentemmanna odi' " yang artinya ornamen Keraton Sumenep mengandung nilai makna dari motif anggrek yang bergulung bersulur merupakan lambang kesuburan, kesempurnaan, dan kemakmuran bagi masyarakat Sumenep. Dengan warna gold yang memberikan makna kejayaan.

Ornamen ini disajikan menggunakan teknik ukir lapaden pada kayu jati, dengan warna merah menjadi warna dasarnya dan warna gold pada motif ornamen, sehingga memberikan kesan kontras terhadap motif yang ditonjolkan, yaitu motif anggrek dengan daun mudah menggulung dan bersulur sepanjang kolom pintu Keraton Sumenep Madura.

\section{c. Ornamen pada Daun Pintu Keraton Sumenep Madura}

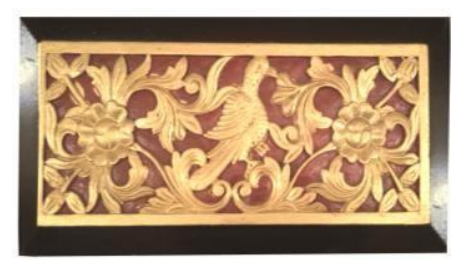

Ornamen yang terdapat pada daun pintu Keraton Sumenep Madura pada gambar 5 tidak hanya dibuat dengan tujuan menghias atau memperindah pintu keraton. Motif pokok yang ditonjolkan, yaitu burung Hong yang memberikan kesan adanya kehidupan, dan tanaman burneh memberikan pelengkap dalam alam, sehingga menimbulkan hubungan erat antara keseimbangan kehidupan yang ada di alam.

Namun d balik nilai keindahan dari motif ornamen, terkandung nilai makna dari motif burung hong (phunix) yang melambangkan kedamaian kehidupan bagi sang raja yang mendiami sebuah Keraton Sumenep maupun masyarakat Sumenep. Warna gold memberikan makna kejayaan.

Ornamen ini disajikan menggunakan teknik ukir lapaden pada kayu jati, dengan warna merah menjadi warna background dan warna gold pada motif ornamen, sehingga memberikan kesan kontras terhadap motif yang ditonjolkan, yaitu motif burung hong yang bertengger di tanaman burneh yang memberikan kesan keseimbangan dalam hidup.

\section{PENUTUP}

Dari segi pewarnaan, warna yang melekat pada ornamen Keraton Sumenep Madura adalah merah, coklat tua, dan dominan warna gold. Hal ini mempunyai kesaman dengan warna Klenteng yang sering menggunakan 
pewarnaan serupa.

Ornamen yang terdapat pada Keraton Sumenep Madura didominasi motif flora yang bersulur, sehingga disebut motif sulur-suluran (Janggolengan). Adapun penekananpenekanan terhadap motif seperti burung Hong (Phunix) merupakan motif yang dipercaya sebagai simbol kedamaian bagi kebudayaan Tiongkok.

Ornamen motif Keraton Sumenep Madura bukanlah motif khas Madura pada umumnya, melainkan terdapat pengaruh akulturasi dari Tionghoa, yaitu dengan adanya pewarnaan warna merah dan warna gold, serta adanya motif burung Hong menjadi bukti adanya akulturasi budaya Madura dan Tionghoa.

Ornamen motif Keraton Sumenep Madura bukanlah sekedar motif yang indah, melainkan terdapat makna di balik keindahannya, yaitu perdamaian atau ketenteraman dalam hidup yang disimbolkan dengan motif burung Hong (phunix), sedangkan tanaman anggrek dan tanaman Burneh merupakan simbol dari kesuburan atau kemakmuran, sehingga motif tersebut didesain untuk mewujudkan harapan kejayaan dan kemakmuran bagi pemerintahan keraton Sumenep Madura.

\section{Ucapan Terima Kasih}

Saya ucapkan bayak terimah kasih kepada Bapak Moh. Soleh selaku pengurus Museum Sumenep, yang telah membantu dalam memberikan informasi berhubungan sejarah arsitektur keraton Sumenep Madura. Saya juga ucapkan terima kasih kepada Bapak Jubri yang merupakan seniman ukir Karduluk Madura, yang telah memberikan informasi berhubungan bentuk-bentuk motif yang terdapat pada pintu Keraton Sumenep Madura.
Dharsono (Sony Kartika), Hj.Suarmi. 2007. Estetika Seni Rupa Nusantara. Surakarta: ISI Press.

Direktorat Jenderal kebudayaan, Depdikbud. 1980. Seni Ukir Madura: Pustaka Wisata Budaya.

Djelantik. 1999. Estetika Sebuah Pengantar. Bandung: Masyarakat Seni Pertunjukan Indonesia arti.line.

Guntur. 2004 Ornamen Sebuah Pengantar. Surakarta: P2AI STSI dengan STSI press.

Gustami.2008. Nukilan Seni Ornamen Indonesia. Yogyakarta.Jurusan Kriya FSR ISI Yogyakarta.

Hakikat Makna Burung Phoenix dalam Tradisi Cina. Rabu 12 November 2014,15:45 WIB. (https://nationalgeographic.grid.id/read/132 95208/hakikat-makna-burung-phoenixdalam-tradisi-cina?page =all)

Kartodirdjo, Sartono. 1993. Pendekatan Ilmu Sosial dalam Metodologi Sejarah. Jakarta: PT Gramedia Pustaka Utama.

Sachari, Agus .2002. Estetika Makna, Symbol Dan Daya. ITB.

Soepratono. 2004. Ornamen Ukir Kayu Tradisional Jawa : Semarang Bffhar.

Sugeng Wardoyo. 2018. "Kajian Estetika Motif Batik Girilayu Kabupaten Karanganyar" dalam jurnal Corak : Jurnal Seni Kriya Vol. 7 No. 2 Desember 2018.

Sumardjo, Jakob. 2000. FilsafatSeni. Bandung: ITB.

Sunaryo, Aryo. 2009. Ornamen Nusantara Kajian Khusus Tentang Ornamen Indonesia. Semarang: Dahara Prize.

Susanto, Mikke. 2011. Diksi Rupa Kumplan Istilah dan Gerakan Seni Rupa.

Suyani. 2013. "Pengaruh Budaya Asing terhadap perkembangan Batik Pekalongan" dalam jurnal Corak : Jurnal Seni Kriya Vol. 2 No. 1 Mei 2013.

4 Ruang Lingkup Sejarah. Kompas.Com. 05/04/2021. 14:08 WIB (https://www.kompas.com/skola/read/2021/ 04/05/140838369/4-ruang-lingkupsejarah?page $=$ all )

\section{DAFTAR PUSTAKA}

